\title{
Los medios electrónicos de difusión comerciales y la instrumentación de su "concepto" de audiencias en México
}

\author{
Javier Esteinou Madrid* \\ Universidad Autónoma Metropolitana, Unidad Xochimilco
}

\section{RESUMEN}

Derivado del modelo dominante de comunicación-mercado que durante muchos años se impuso para la operación de las industrias culturales electrónicas en México, las audiencias fueron concebidas y tratadas durante décadas desde la lógica del mercado y del poder como simples receptores pasivos que debían consumir o asimilar mensajes mediáticos para asegurar los intereses de los emisores más fuertes. De esta manera, el aparato mediático transformó a los ciudadanos en espectadores pasivos de la producción mediática cotidiana para fortalecer su proceso económico y político.

Con ello, se eliminó que los auditorios contaran con capacidades de acción comunicativa para responder ante los mismos generando sus propias respuestas o mensajes ante los emisores y la sociedad. De aquí, la gran importancia que la sociedad respalde los Derechos de las Audiencias que la Reforma de las Telecomunicaciones y la Radiodifusión del 2013 introdujo en la Constitución Política Mexicana como una garantía comunicativa histórica para los receptores.

Palabras clave: industrias electrónicas, mercadotecnia, televisión, receptores, reforma telecomunicaciones, derechos de audiencias

\begin{abstract}
Derived from the dominant model of communication-market that for many years was imposed for the operation of the electronic cultural industries in Mexico, the audiences were conceived and treated for decades from the logic of the market and of the power like passive receptors that they had to consume or to assimilate Media messages to ensure the interests of the strongest issuers. In this way, the media apparatus transformed citizens into passive spectators of everyday media production to strengthen their economic and political process.
\end{abstract}

\footnotetext{
*Investigador Titular del Departamento de Educación y Comunicación de la Universidad Autónoma Metropolitana, Unidad Xochimilco, Ciudad de México. Correo electrónico: jesteinou@gmail.com
} 
With this, it was eliminated that the audiences would have capacities of communicative action to answer before the same generating their own answers or messages before the issuers and the society. Hence, the great importance that society endorses the Rights of Hearings that the Telecommunications Reform and Broadcasting of 2013 introduced in the Mexican Political Constitution as a historical communicative guarantee for the recipients.

Key words: electronic industries, marketing, television, receivers, telecommunications reform, rights of audience 


\section{EL SURGIMIENTO DEL SISTEMA DE COMUNICACIÓN COMERCIAL PRIVADO EN MÉXICO}

Debido al modelo de desarrollo global adoptado por la sociedad mexicana durante el siglo XX, especialmente después del proceso de industrialización nacional, la naturaleza social de los medios de comunicación, particularmente electrónicos, desde su origen a la fecha, quedó determinada por la existencia de poderosos factores económicos, políticos y culturales que condicionaron que tales instituciones se desenvolvieran bajo el modelo empresarial. Dicho prototipo comunicativo se caracterizó fundamentalmente por funcionar bajo la dinámica de la comunicación-mercado buscando como objetivo prioritario el recaudar las mayores ganancias económicas y políticas, pasando sobre cualquier otra realidad que le representara un obstáculo.

Condicionada por estos factores estructurales la televisión mexicana surgió en la década de los años cincuentas adoptando el modelo comercial privado de desarrollo de la televisión norteamericana y enmarcó mayoritariamente su funcionamiento bajo el régimen de concesión comercial particular que conserva hasta nuestros días. Dicho modelo se caracterizó por ser "uno de sistemas más altamente concentradores y monopólicos del mundo por su fuerte discrecionalidad, al grado que a principios del siglo XXI las reglas que existen son las de un duopolio asimétrico con un jugador predominante que es Televisa" (Zabludovsky Nerubay, 2002, pp. 211 y 212).

Así, por ejemplo, antes del proceso de digitalización el grupo Televisa contaba con 306 estaciones de televisión que abarcaban el $80 \%$ del auditorio nacional y el 70\% de todos los presupuestos de publicidad en México.

Televisión Azteca poseía 180 estaciones, acaparando el 20\% del auditorio y el $30 \%$ de la publicidad, y el resto de las empresas tenían que sobrevivir con las migajas que quedaban.

Con ello, estas dos empresas de televisión generaron una problemática de concentración de medios en la misma ciudad, propiedad cruzada de empresas, monopolización de las cuotas de producción nacional, acceso a producciones independientes en los horarios de mayor audiencia, relación sin límites con los inversionistas extranjeros, control de los topes de mercado para ser explotados por estaciones de una sola empresa, concentración de todas las formas de producción y distribución de la programación en México en una compañía mayoritaria, desperdicio escandaloso de canales dedicados a la reventa de señales de formatos y programación extranjera, imposibilidad de participación de la sociedad en la 
revocación o refrendo de las concesiones, renta de estaciones, etc. ("La impunidad en México”, 2003, p. 45).

En cuanto a la radio comercial, el 76\% del sector se encontraba en manos de 14 familias y solo cuatro grandes cadenas aglutinaban casi la mitad del total de las emisoras (47.8\%). Realidades que son impensables en otros países ("Sociedad civil al rescate", 2003).

Dicho fenómeno histórico propició que los medios de difusión electrónicos, particularmente la televisión, se desarrollaran a lo largo de muchas décadas prioritariamente bajo el modelo de comunicación mercado (Esteinou, 2001, pp. 193-237) y no bajo el prototipo de comunicación de servicio público, generando diversas repercusiones de desigualdad cultural, comunicativa, ciudadana y civilizatoria para la sobrevivencia de la sociedad mexicana (Navarro Benítez, 2013, pp. 37 a 46).

Fue dentro de este esquema privado mercantil que la radiodifusión nacional, particularmente la televisión, se desarrolló mayoritariamente, y donde alcanzó hasta ahora su principal dinámica de expansión e influencia cotidiana sobre la cultura y la conciencia nacional.

Con ello, el modelo de comunicación mercado se consolidó como la dinámica fundamental que esculpió la superestructura cultural de la sociedad durante más de la mitad del siglo XX y las primeras décadas del siglo XXI en México.

\section{CARACTERÍSTICAS DEL MODELO DE COMUNICACIÓN-MERCADO}

$\mathrm{El}$ funcionamiento del modelo de comunicaciónmercado en México durante varias décadas se distinguió esencialmente por concebir los procesos de comunicación como meros instrumentos tecnológicos y dinámicas simbólicas destinadas a consolidar el proceso de acumulación de capital y sostener las relaciones de poder del status quo en la República.

En este sentido, los medios de difusión y sus flujos de transmisión de información correspondientes fueron empleados como ágiles herramientas para apuntalar al sistema económico y político prevaleciente y no para incrementar la participación ciudadana o crear una nueva conciencia orgánica para la sobrevivencia colectiva en la nación.

De esta forma, para ser eficientes en tales áreas éste modelo introdujo intensivamente los principios del "laissez faire informativo" en el terreno comunicativo o cultural, o lo que fue lo mismo, asumir la mentalidad de que "lo que no deja dinero a nivel cultural, no sirve".

Bases que, llevadas a sus últimas consecuencias, en la práctica real plantearon el 
peligro de que, en lugar de fortalecer nuestra cultura nacional, esta tuvo que flexibilizarse, y en ocasiones, hasta erosionar más sus valores para incorporarnos eficientemente como sociedad y sin restricción alguna a la nueva estructura de competencia y de concentración de los mercados mundiales.

Históricamente esta dinámica estructural del manejo de la comunicación colectiva se acentuó significativamente a partir de los años ochenta. cuando el proceso acelerado de incorporación de México a la apertura y globalización mundial, exigió, por una parte, el retiro del Estado como instancia rectora de la comunicación, y por otra, la imposición de las fuertes políticas econométricas neoliberales para convertir al Estado mexicano en una entidad "altamente eficiente $y$ rentable" cuya tarea esencial fue la facilitación de las condiciones para la realización del capital a escala nacional e internacional.

Dicha realidad generó simultáneamente una severa crisis estructural y la desaparición paulatina del modelo de medios de comunicación de servicio público que durante tres décadas habían funcionado frágilmente en México; para dar paso mayoritariamente al proyecto de comunicación-mercado con sistemas de información privados altamente mercantilizados.

Es decir, debido a que las leyes de la "libre competencia" exigieron que las em- presas contendieran entre sí con sus propios recursos y sin apoyo estatal, el gobierno mexicano retiró gradualmente los subsidios que fortalecían a los medios públicos, y no obstante que éstos son medios de Estado que ejecutan funciones distintas a las del prototipo comercial privado, cada vez más, han tenido que luchar con sus propios apoyos para sobrevivir ante la fuerte presión de las empresas privadas.

La implementación de este modelo económico globalizador de la comunicación contribuyó de manera sustantiva a reforzar pragmáticamente la situación de las audiencias como sectores meramente receptivos de los productos simbólicos mass mediáticos.

En este sentido, la aplicación prioritaria de este diseño económico-político de los medios de difusión colectivos fue fundamental para definir, directa e indirectamente, cómo tendrían que ser las audiencias de las industrias mediáticas en México, particularmente televisivas.

Esto es, el tipo de audiencias o públicos mediáticos que surgieron en el país, no emergieron espontáneamente o como reconocimiento de una garantía jurídica ciudadana; sino que nacieron determinadas por el funcionamiento comercial dominante que existía en los medios de información colectivos en la nación, y no por otras visiones de servicio público sobre los mismos. 


\section{LAS AUDIENCIAS DENTRO DEL PROTOTIPO DEL "LAISSEZ FAIRE COMUNICATIVO"}

Derivado del modelo dominante de comunicación-mercado que durante muchos años se impuso para la operación de las industrias culturales, especialmente electrónicas, en México las audiencias de estas fueron concebidas y tratadas durante décadas desde la lógica del mercado y del poder como simples receptores pasivos que debían consumir o asimilar mensajes mediáticos de diversa índole (comerciales, políticos, institucionales, etc.) para asegurar los intereses de los emisores más fuertes, pero sin contar con capacidad de acción comunicativa para responder ante los mismos, generando sus propias respuestas o mensajes para la sociedad. Así, el concepto de "audiencia fue una creación derivada de la unilateralidad de los medios de comunicación, que se dirigen en un solo sentido, y lo que crean son justamente escuchas, gente que oye y calla, que ve y se silencia, y cuando mucho, de vez en cuando, intenta comunicarse" (Caballero Pedraza, 2014, pp. 20 y 21).

Este modelo dominante de tratamiento encapsulado de los auditorios por el prototipo comercial del aparato mediático ocasionó que las diversas audiencias de los medios electrónicos de difusión colectivos solo fueran consideradas calculadamente bajo dos ópticas pragmáticas: por un lado, desde las necesidades de reproducción económica de la estructura social y, por otro lado, desde la perspectiva política de evolución del país.

Así, por una parte, desde el ángulo del funcionamiento económico de la sociedad, las industrias mediáticas electrónicas utilizaron a los públicos como consumidores netos de los productos y servicios que anunciaban, sin darles ninguna opción de participar como emisores dentro del espacio público mediático. Debido a ello, las diversas audiencias de los medios electrónicos de difusión colectivos fueron contempladas mercadológicamente siguiendo las directrices de las agencias de publicidad como simples sectores sociales estratificados con potencial económico y conductas consumidoras diferenciadas según fuera su capacidad adquisitiva en niveles " $A$ ", " $B$ ", " $C$ " o " $\mathrm{D}$ " y subsectores menores, para obtener las mercancías o servicios que se anunciaban en las pantallas o diales de las industrias culturales.

Tales estratos de auditorios se reconocen a partir de comportamientos muy específicos de consumo que caracterizan a cada sector de públicos, pero ningún elemento de naturaleza o competencias comunicativas. Así, por ejemplo, el “nivel 'A Alto Superior' se distingue porque las amas de casa no to- 
man decisiones de compra en artículos de primera necesidad, la cocinera es quien lo hace. Las familias no son influenciadas por la publicidad en tv, ya que sus actividades no les permiten verla. Tienen una casa de fin de semana en la playa u otro lugar de descanso. Poseen tarjetas de crédito internacionales y realizan más de dos viajes al extranjero al año. No reacciona ante las influencias nacionales, ya que compran con base en la moda del extranjero. Buscan exclusividad y diseños especiales. Adquieren automóviles importados y elegantes, para hacer gala del estrato al que pertenecen. Gran cantidad de sus compras son superfluas" (Contreras Rodríguez, 2012).

'El nivel 'B Alto Inferior' se identifican porque tienen a su servicio una cocinera, quien decide las compras de primera necesidad. Generalmente compra en tiendas de autoservicio. No están expuestos a la publicidad, por lo que no reaccionan a los estímulos externos nacionales. Las compras de productos como enseres domésticos y muebles las realizan en tiendas especializadas. La mayoría de las decisiones de compra las hacen en pareja; muchas son superfluas e innovadoras. Buscan ropa de calidad y artículos de moda de diseñadores mundiales. Prefieren comprar en el extranjero, ya que los consideran de mayor calidad. Compran automóviles del año y elegantes. Poseen tarje- tas de crédito internacionales, por lo regular hacen dos o más viajes al extranjero por año” (Contreras Rodríguez, 2012).

“El nivel 'C Medio Superior' se diferencia porque las compras de artículos de primera necesidad las hace el ama de casa, ya que es quien conoce mejor esas necesidades. Es común que estas compras se realicen mensual o quincenalmente en tiendas de autoservicio. Poseen tarjetas de crédito nacionales e internacionales. Viajan por lo menos una vez al año al extranjero. Las decisiones de compra son tomadas en pareja, y muchas están influenciadas por el medio en el que viven. En cuanto a ropa, buscan estar a la moda con diseños de marca. Desean imitar a personas de estratos similares o mayores, por lo que adquieren gran cantidad de artículos superfluos. Reacciona a la publicidad transmitida en los medios" (Contreras Rodríguez, 2012).

“El nivel 'C Medio' se ubica porque compran productos que ya conocen; no son leales a una marca; adquieren muchos productos en promoción; realizan sus compras quincenalmente en tiendas de autoservicio, aunque acuden a mercados por otros productos; las compras son en pareja. Reacciona ante influencias externas y la publicidad por televisión, lo que modifica su comportamiento. En cuanto a ropa, buscan calidad a precio accesible. Reaccionan ante las tempo- 
radas baratas de grandes almacenes, donde también suelen adquirir mobiliario. Generalmente compran a crédito; poseen una tarjeta de crédito nacional. Acostumbran hacer un viaje nacional de vacaciones al año" (Contreras Rodríguez, 2012).

'El nivel 'D Bajo Superior' se reconoce porque la actitud del ama de casa es quien realiza las compras de primera necesidad, principalmente en lugares más económicos (central de abastos, mercados sobre ruedas, etcétera). Compras semanales; reaccionan ante la publicidad y las promociones. Los muebles y artículos electrodomésticos los compran a crédito en mueblerías. Adquieren su ropa en tiendas del centro; no buscan marcas sino precio y durabilidad. Se visten a la moda con marcas piratas, consideran un logro comprar productos de calidad a bajo precio. Compran muchos productos extranjeros a vendedores ambulantes" (Contreras Rodríguez, 2012).

‘El nivel 'D Bajo' donde la economía es muy limitada, se definen porque el ama de casa es quién realiza diariamente sus compras, aunque dedica un día a la semana para hacer compras mayores en la Central de Abastos. Es común que realicen compras en tiendas de la esquina y tianguis. Los muebles y electrodomésticos los compran en abonos en mueblerías del centro. La decisión de compra depende del jefe de familia. Creen mucho en la publicidad y promociones, pero no pueden comprar lo que se anuncia. Son leales a ciertos productos y marcas, y el precio determina la compra. La ropa es adquirida en tiendas del centro, en tianguis o con vendedores ambulantes" (Contreras Rodríguez, 2012).

'Finalmente, el nivel ' $E$ ' se registra porque las amas de casa realizan sus compras en tiendas de esquina diariamente, comprando muchas veces más caro. Compran los muebles por piezas sueltas a crédito en mueblerías con pagos semanales. Reaccionan muy poco a la publicidad. Compran ropa en tiendas del centro, mercados sobre ruedas, vendedores ambulantes, etc. Este segmento está apoyado por programas gubernamentales: 'canasta básica', leche a bajo precio, vales para tortillas, servicios de salud gratuitos, etc." (Contreras Rodríguez, 2012).

Con dicho protocolo mercadológico comunicativo las empresas de difusión masiva elaboraron de manera diferenciada sus mensajes según fueran las capacidades adquisitivas de cada sector receptor y no con base en las necesidades básicas de desarrollo elemental de los mismos. Así, se reforzó la estructura de la sociedad de consumo y no de la ciudadanización de la sociedad que es el estamento fundamental que requiere el país para avanzar civilizatoriamente.

Por otra parte, desde la mirada política, 
particularmente, durante los períodos electorales, los partidos y los medios convirtieron a los ciudadanos en meros auditorios cautivos que únicamente contemplaron la versión privada de lo público que estos transmitieron, sin crear condiciones para que los auditorios se transformaran en sujetos activos con capacidades para participar interactivamente en la construcción de la nueva plaza pública mediática través de la generación de sus comunicaciones específicas. De esta forma, los ciudadanos quedaron reducidos a espectadores o a individuos con status de ciudadanía de muy baja intensidad.

En este sentido, siguiendo las directrices de la escuela de la telepolitica y sus derivados espectaculares, los partidos políticos nunca permitieron que los votantes discutieran sus diversas propuestas de gobernabilidad con los distintos candidatos a los puestos de representación popular, especialmente a la presidencia de la República. Lo único que los motivó fue el acceso oportunista a los tiempos oficiales en radio y televisión para difundir abusivamente su imagen virtual a través de la transmisión de millones de spots para legitimarse ante los auditorios como fracciones en el poder.

Ocasionado por la imposición de tal práctica los partidos no admitieron el avance de la verdadera política sustantiva que implica el análisis, la reflexión y la discusión plural de las diversas formulaciones que plantean los candidatos ante los principales conflictos de desarrollo del país y la búsqueda de las mejores opciones de solución de los mismos, sino su objetivo fue el progreso de la telepolítica, que implica el uso de recursos mediáticos de la propaganda más espectacular para ideologizar a los auditorios, con el exclusivo fin calculado de ganar votos momentáneos y triunfar electoralmente (Esteinou Madrid, 2010 y 2011).

De esta manera, el aparato mediático creó la gerencia electrónica colectiva que transformó a la población en consumidores cautivos; y a los ciudadanos en espectadores pasivos de la producción mediática cotidiana que se generan para fortalecer el proceso económico y político del país. Fue el triunfo significativo de la mercadotecnia fenicia de los medios masivos sobre la necesidad estratégica de edificar el proceso de ciudadanización de la comunicación colectiva en México.

Así, bajo cualquiera de las dos perspectivas anteriores, la económica o la política, los ciudadanos, los grupos emergentes o la sociedad civil organizada de principios del Tercer Milenio en la República mexicana, continuó siendo simplemente una comunidad receptora y no emisora de mensajes. Las únicas excepciones de participación de la ciudadanía en los medios de información colectivos se dieron cuando alguno de éstos 
sectores, por determinadas circunstancias excepcionales, se convirtieron en "noticia sorpresiva", o en "objetos simbólicos" coyunturales, difundiéndose por los medios como las mercancías informativas del momento que podían elevar el rating comercial de las empresas y desaparecieron de las pantallas o diales cuando dejaron de ser atractivos para los televidentes, sin contar con garantías jurídicas para continuar participando en dichos espacios cuando ellos lo requirieran para elaborar su propia opinión pública en el espacio público mediático.

En otras palabras, la sociedad civil o los grupos emergentes solo pueden participar en la programación de los medios cuando sirven como apoyo para incrementar la penetración de las empresas radiotelevisivas, pero no son contemplados permanentemente dentro de las barras informativas de las industrias culturales electrónicas como sujetos o entidades con derecho a disponer con espacios constantes de expresión colectivos para producir corrientes de opinión y de participación social. Por consiguiente, es solo la lógica de oportunidad económica del raiting la que decide quién, cuándo y en qué grado participa la sociedad civil dentro de los medios y en qué momento no; y no la existencia operativa de un cuerpo jurídico de garantías ciudadanas comunicativas básicas existentes en nuestra Constitución que han de- mandado los ciudadanos desde hace cinco décadas en el país.

Ejemplo de ello fue la difusión de forma intensiva durante una o dos semanas, que se dio en los medios electrónicos nacionales en el año 2005 sobre la existencia de los sectores paupérrimos como grupos damnificados, que salieron a la luz pública por los efectos devastadores que les provocaron los huracanes Katrina, en Nueva Orleáns, EUA; Stan, en Chiapas; y Wilma en Cancún; y después fueron olvidados radicalmente por la programación de las industrias culturales, y nunca más se volvió a hablar de ellos en las pantallas o diales.

Sin embargo, paradójicamente, mientras en ese contexto histórico de hermetismo comunicativo las grandes comunidades no tuvieron alternativas de presencia en los medios, la distribución desigual de acceso a la estructura de información masiva, permitió por ejemplo, que de marzo a junio del 2002, el consorcio Televisa pudo utilizar tres canales del sistema Sky para transmitir las 24 horas del día la programación completa de la telebasura frívola, insustancial y vacua de la primera versión de Big Brother durante tres meses y medio.

En síntesis, la única garantía de participación que alcanzó la sociedad mexicana después de más de nueve décadas de existencia de la radio y más de seis décadas de 
presencia de la televisión en la República, fue el derecho de cambiar de canal o frecuencia, o de apagar o encender la pantalla, pues de manera real, ningún otro derecho fue otorgado por la tradicional estructura de poder mediático nacional, especialmente en la etapa de apertura de fronteras comerciales.

De esta manera, en el ámbito de la comunicación colectiva durante varias décadas asistimos en México a la presencia de un Estado fallido que se caracterizó por no defender comunicativamente a los ciudadanos convertidos en audiencias subordinadas, sino solo protegió los intereses de expansión de los grandes monopolios informativos que se consolidaron en el país, particularmente con el proceso de globalización.

\section{LA FORMACIÓN DE LOS AUDI- TORIOS MEDIÁTICOS}

Partiendo de las concepciones reduccionistas sobre el entendimiento de los auditorios que se impusieron en el país, las industrias culturales electrónicas gradualmente establecieron sus poblaciones singulares mediante la formación de sus propios auditorios o públicos especializados para cada medio electrónico masivo.

Así, la radio generó asiduos radio escuchas fieles y la televisión grandes sectores de televidentes compulsivos que asimilaron cotidianamente la producción simbólica de cada medio, transformando gradualmente sus referentes cognitivos, y con ello, sus estructuras culturales.

Dicha tendencia de proliferación acelerada del tejido tecnológico sobre el campo de acción de la sociedad se acentuó tanto, especialmente en el terreno audiovisual, que la televisión se convirtió para las comunidades, especialmente urbanas, en la principal fuente básica de conocimiento y educación cotidiana de la realidad. Así, la multiplicación y penetración tecnológica de esta gran infraestructura informativa en el país, particularmente electrónica, contribuyó a modificar sustancialmente los tradicionales hábitos culturales de la vida cotidiana de los mexicanos, particularmente en el núcleo familiar.

En esta forma, al final del siglo XX el promedio de exposición de la familia mexicana a la televisión fue superior a 49.5 horas por semana, convirtiendo a los mexicanos en los habitantes que más veían televisión en todo el continente americano, con un promedio diario superior a las cuatro horas (Los mexicanos pasan más horas..., 1998). Sin embargo, para principios del siglo XXI esta tendencia se incrementó provocando que "los adultos en las ciudades vieran en promedio once horas de televisión a la semana, y estimándose que a la edad de setenta años una persona en México habrá pasado entre siete y 10 años de su vida frente a un televi- 

sor" (Vázquez Mota, 2005, p. 5). Los ado-
lescentes entre 12 y 17 años en las zonas urbanas ven actualmente catorce horas de televisión a la semana, y la mitad de los niños entre los 6 y 11 años ven tres horas $o$ más de televisión diariamente en promedio, y esta práctica continúa en aumento con la expansión vertiginosa de los nuevos sistemas de televisión por cable, la suscripción a domicilio, la presencia de la televisión directa, las tecnologías de comunicación interactivas, la expansión de las nuevas tecnologías de información en nuestro país, y las campañas mercadológicas para conquistar el aumento de exposición diaria a los medios audiovisuales ("La violencia televisada produce graves...”, 1992).

De esa tendencia creciente de exposición a la televisión, el $81 \%$ de los menores de edad observaron la televisión sin ninguna supervisión, pasando un promedio de 25 horas a la semana frente a la pantalla. Los temas que más se difundieron en el 2005 dentro de la programación de los monopolios televisivos fueron chismes (89\%), violencia $(83 \%)$, vulgaridad $(80 \%)$ y desorden sexual (18\%) ("Ve $81 \%$ de los menores la tv...", 2005).

En relación a la exposición a los medios a nivel nacional por parte de la población adulta en México, se constató que, por ejemplo, en el año 2010 el $76 \%$ de los encues- tados por el Consejo Nacional Para la Cultura y las Artes (Conaculta) reflejaron que no escuchaban la radio y solo el $24 \%$ atestiguó que si la escuchó. De ese total de receptores el $33 \%$ la oyeron más de una hora, el $27 \%$ entre una y dos horas, el $22 \%$ más de dos horas, el 16\% media hora y el $2 \%$ no sabe (“Encuesta nacional de hábitos...", 2010, pp. 149 y 150).

En cuanto a la televisión se confirmó que en el año 2010 el 90\% de la población adulta miró la pantalla y el 10\% no la vio. De ese porcentaje total que recibía la televisión el $40 \%$ vio la televisión dos horas diarias, el 35\% entre una hora y dos horas, el $19 \%$ una hora, el $5 \%$ media hora y el $1 \%$ no contestó ("Encuesta nacional de hábitos...", 2010: 152 y 153).

De esta manera, los referentes cognoscitivos cotidianos de los ciudadanos mexicanos de diversas edades, para informarse, construir su opinión diaria y actuar socialmente, provinieron crecientemente de los medios radiotelevisivos y no de las fuentes escritas o culturales convencionales que formó durante muchas décadas el Estado nacional u otras áreas de socialización de las comunidades. En este sentido, la población se entera en un mayor grado de los hechos políticos que acontecen en la vida diaria por intervención de la televisión y de la radio y en menor grado por la prensa, las revistas, 
los anuncios de partidos, los posicionamientos del presidente de la República, las declaraciones de diputados y senadores, los pronunciamientos de funcionarios públicos, los programas políticos, las conversaciones familiares, el internet, los amigos, los vecinos, las personas y las asambleas. Así, por ejemplo, en la primera década del siglo XXI en México los ciudadanos adquirieron los referentes políticos de su vida cotidiana de las siguientes fuentes de conocimiento: $88.6 \%$ de la televisión; $50.6 \%$ de la radio; $43.7 \%$ de la prensa; $29.6 \%$ de conversaciones familiares; $25.1 \%$ de posicionamientos del presidente de la República; $23.4 \%$ de amigos, vecinos, personas y asambleas; $14.5 \% \%$ de anuncios de partidos; $13.3 \%$ de las revistas; $12.2 \%$ de declaraciones de diputados y senadores; $12.4 \%$ de programas políticos; 11.6 $\%$ de pronunciamientos de funcionarios públicos; y finalmente; $7.2 \%$ de internet (Informe ENCUP 2008, pp. 133 a 139).

Con esta transformación tecnológico cultural, a principios del nuevo milenio la población mexicana se transformó de una cultura de lectores a una cultura de televidentes, de lo cual se derivó un peso muy sustantivo de los medios audiovisuales, especialmente privados, en la formación de sus gustos, valores, imaginarios, opiniones, deseos, mentalidades, visiones de la vida, actitudes y conductas, en una idea, de la for- mación y operación de sus cerebralidades y emocionalidades de los grupos sociales. Esta asombrosa expansión tecnológica material de los medios de información creó a principios del siglo XXI una sociedad mexicana altamente mediatizada en sus procesos colectivos de interacción que cambió radicalmente las formas tradicionales de convivencia, organización, participación e inserción comunitarias.

\section{EL MODELO DE COMUNICACIÓN PARA LOS JODIDOS}

A partir de los grandes condicionantes históricos de control político aplicados al funcionamiento de los medios electrónicos de información en México, se construyó por décadas en el país un modelo dominante de comunicación que se distinguió por ser monopólico (duopólico en la televisión y oligopólico en la radio); vertical; concentrado; unidireccional; hermético; elitista; frívolo, discrecional; frívolo, autoritario; excluyente de los grandes grupos sociales; restrictor de la libertad de expresión e impulsor de la libertad de empresa; promotor de la difusión de la información y no de la dinámica de la comunicación; negador de los derechos comunicativos elementales de los ciudadanos; fomentador de la dinámica de mercado y no del servicio público, y que finalmente, dio voz y participación a una 
minoría y silencio u olvido para la mayoría nacional.

Mediante ello, se anuló el ejercicio de un verdadero Derecho a la Información, del Derecho de Réplica, del Derecho de Acceso a la Comunicación, del Derecho de Defensa de su Imagen en los medios, etc. Tal prototipo de comunicación se denominó como el Modelo de Comunicación para los Jodidos que fue impulsado ampliamente por los grandes monopolios de la difusión masiva en el país y se distinguió por construir esclavos mentales domesticados y no ciudadanos conscientes capacitados para participar en la construcción de una nueva sociedad más plural y equilibrada (Esteinou Madrid, 2013).

Este prototipo de difusión masivo populista fenicio, fue la matriz que acuñó la naturaleza del tipo de auditorios mediáticos que se instalaron en el país durante muchas décadas, creando profundas consecuencias civilizatorias para la sociedad mexicana durante el siglo XX y siglo XXI.

La presencia de este modelo de comunicación desigual construyó un tipo de audiencias que fue una pieza estructural fundamental que colaboró de forma sustancial a conservar por más de siete décadas al viejo régimen político del Partido Revolucionario Institucional (PRI) en el país en el siglo XX, se prolongó durante la "transición pacífica a la democracia" del año 2000 al 2012, y continuó manteniéndose vigente con el regreso del PRI a la presidencia de la República del año 2012 en adelante en México. Así, durante el siglo XX en México, el modelo de comunicación, el modelo de gobernabilidad vertical del PRI y el modelo de poder de la antigua clase política, vía complicidades, secrecías y canonjías, siempre fueron de la mano para conservar el sistema político autoritario más largo de toda la histora del México moderno.

Esta alianza histórica de los concesionarios de los medios de información electrónicos ante los intereses políticos del sector dominante se reflejó nítidamente cuando, por una parte, Emilio Azcárraga declaró textualmente que "Televisa era soldado del Partido Revolucionario institucional (PRI) y, por lo tanto, su política informativa apoyaba a ese sector político". Por otra, cuando frente a la campaña para las elecciones presidenciales del año 2000, Televisa y Televisión Azteca, le dieron sustanciales descuentos al PRI para que su propaganda televisiva electoral le rindiera casi nueve veces más, en promedio, que a los otros partidos opositores. De ésta forma, debido a que la ley electoral de ese momento no podía regular descuentos de los medios electrónicos a los partidos, Televisa le otorgó al PRI un descuento de $89.47 \%$, a la Coalición Alianza por el Cambio (PAN- 
PVM) $52.10 \%$, y ninguna disminución a la Coalición Alianza por México (PRD-PTCD-PAS-PSN). Con ello, un spot de propaganda le costó al PRI 9.5 veces menos que al Partido de la Revolución Democrática y 4.5 veces menos que al Partido Acción Nacional ("Elecciones 2000...”, 2002, pp. 9 a 13).

Por su parte, Televisión Azteca le concedió al PRI un descuento de $74.62 \%$, a la Coalición Alianza por el Cambio 62.96 \% y a la Coalición Alianza por México nada, reflejando el pacto que las televisoras realizaron con cada grupo político ("Favorecen en 2000 televisoras al PRI", 2003).

Las consecuencias del impacto político, social y cultural de la aplicación de dicho modelo de información alcanzaron su mayor precisión conceptual cuando el intelectual Carlos Monsivais declaró en los años ochenta. "que en México el verdadero Ministerio de Educación era Televisa y no la Secretaría de Educación Pública (SEP) y que gracias a la programación de la televisión mexicana ya habían nacido varias generaciones de norteamericanos en México". Esta realidad obtuvo su culmen de expresión despótica cuando don Emilio Azcárraga Milmo, presidente y accionista mayoritario de la empresa Televisa, externó en 1993 en su célebre reunión anual de planeación de la que “estamos en el negocio del entretenimiento y de la información, y podemos educar, pero fundamentalmente entretener... México es una clase modesta muy jodida, que no va a salir de jodida... para la televisión es una obligación llevar diversión a esa gente y sacarla de su triste realidad y de su futuro difícil..." ("Televisa no está vinculada...", 1993). Por lo tanto, Televisa se comprometió a producir televisión para los jodidos, pues la naturaleza de México era la de un país de jodidos.

En pocas palabras, para el Modelo de Comunicación para los Jodidos las audiencias o los pobres o los jodidos, vía la televisión, no deben lograr pensar, participar, cuestionar y decidir, sino sólo entretenerse, divertirse, soñar, distraerse, fugarse de la realidad, subordinarse y dejarse dirigir por los medios electrónicos, particularmente por la televisión. Esto es, recibir cotidianamente pan y circo desde la estructura audiovisual mediática tecnológicamente más avanzada del país y no obtener educación, cultura y espiritualidad que le permitan a los auditorios conocer y superar las condiciones de vida que los someten.

De esta forma, durante muchos sexenios funcionó en el país esta tendencia comunicativa y cultural cuya esencia, con distintos matices, adaptaciones y características, fue el prototipo informativo que, en 
mayor o menor grado, también siguieron y aplicaron las otras instituciones comerciales de televisión en la República, hasta nuestros días

A su vez, el Estado mexicano de los últimos 40 años aportó su respectiva cuota de cinismo, complicidad, manipulación $y$ prepotencia para conservar dicho Modelo de Comunicación para los Jodidos al no reglamentar durante cuatro décadas y media el Derecho a la Información y la Ley Federal de Radio y Televisión, ni incorporar ninguna de las miles de propuestas planteadas en los foros populares, las consultas públicas y los espacios ciudadanos de discusión organizados por los gobiernos en turno para examinar y transformar el proyecto de comunicación de la República y crear los Planes Sexenales de Desarrollo en esta materia. En todos ellos, se concluyó siempre con la frase célebre inmovilizadora de "no encontrarle en términos comunicativos la cuadratura al círculo" y en otros momentos argumentar que "reglamentar el Derecho a la Información conllevaría más riesgos que beneficios".

En síntesis, podemos decir que, al funcionar como Primer Poder Ideológico, los medios electrónicos se convirtieron en las extensiones de punta del poder que los controla y no en la ampliación del poder de toda la sociedad que los financió y que solo recibió sus consecuencias mediáticas por decenios. Los medios se transformaron en el monopolio del poder que generó una mediocracia que durante muchas décadas contribuyó sustancialmente a producir un país de siervos obedientes y no de seres pensantes y actuantes críticos.

De esta manera, la hermética estructura de control de los medios ocasionó, cada vez más, que las políticas públicas se elaboraran desde los criterios e intereses privados y no desde las dinámicas colectivas de las mayorías nacionales. En este sentido, en nuestro país las necesidades de la reproducción del gran capital y los motivos del viejo poder fueron los ejes desde donde se reprodujo cotidianamente lo colectivo y lo público y no desde las necesidades de avance de los ciudadanos. Así, abiertamente frente a nuestras narices, durante varias décadas, el espacio público generado por los medios electrónicos se privatizó, transformando lentamente los aspectos privados en públicos y los públicos en privados, adquiriendo lo público las características de una mercancía más regida por las leyes del marketing.

En este sentido, gradualmente el espacio público de la sociedad mexicana crecientemente quedó construido por la acción informativa del modelo de comunicaciónmercado, regido por la lógica de la mano invisible del mercado y no por el modelo de co- 
municación de servicio público y el fomento del bien común.

Con la magna concentración de poder que lograron los canales de información electrónicos en México, paulatinamente construyeron un Estado dentro del Estado tradicional que permitió que ampliaran sus concesiones de fuerza e influencia. Así, mientras la estructura de la comunicación social se convirtió en el Primer Poder Ideológico que vigila, juzga, fiscaliza y somete a todas las áreas del funcionamiento, público $\mathrm{y}$ privado, de nuestra sociedad, especialmente del Estado-gobierno; al mismo tiempo es el único poder autocrático que en la práctica política permanece sin ser supervisado a fondo por el interés colectivo y cada vez más, se propuso la autorregulación como herramienta básica para el acotamiento de los medios y no la ley como reflejo elemental del interés social. Con ello, se realizaron múltiples grados de impunidad desde estos ante la ciudadanía, sin que existan eficientes límites contenedores que los acoten. De esta forma, durante décadas nos enfrentamos a la existencia de un cerebro colectivo, cada vez más privatizado, mercantilizado desbocado y desvinculado del abordamiento de los grandes problemas nacionales, que controló y dirigió al resto del cuerpo social.

Toda esta realidad histórica desigual se fortaleció más a partir de los años ochenta. con la aplicación del modelo de comunicaciónmercado cada vez más desregulado que fomentó el proceso de apertura, modernización y globalización de México, ocasionando una grave crisis cultural, moral y espiritual de nuestra sociedad.

\section{EL RECONOCIMIENTO DE LOS DERECHOS DE LAS AUDIENCIAS POR EL ESTADO MEXICANO}

Derivado del establecimiento de esta fuerte herencia mercantil de muchas décadas, que no reconoció los derechos comunicativos básicos de los ciudadanos, la Reforma de las Telecomunicaciones y la Radiodifusión del año 2013, introdujo históricamente en la Constitución Política Mexicana los Derechos de las Audiencias como una garantía comunicativa que debían gozar todos los receptores. Posteriormente, el Instituto Federal de Telecomunicaciones (Ifetel) fortaleció dichos derechos al publicar el 21 de diciembre de 2016 los Lineamientos Generales Sobre la Defensa de las Audiencias para todos los medios de comunicación electrónicos en México, con el fin de que entraran en vigor el 16 de febrero del mismo año al publicarse en el Diario Oficial de la Federación (DOF) ("Acuerdo mediante el cual el pleno...", 2016).

Mediante estas directrices oficiales los receptores de los medios de comunicación 
electrónicos dejaron de ser considerados por la Ley como meros consumidores de mensajes y fueron elevados jurídicamente a la categoría de audiencias con garantías constitucionales cardinales que el Estado y los concesionarios de las industrias electrónicas debían respetar y fomentar.

Desde el punto de vista civilizatorio este reconocimiento normativo fue un avance histórico fundamental equivalente al reconocimiento que en su momento el Estado otorgó a los pobladores de la República mexicana para que evolucionaran de ser contemplados como simples habitantes del extenso territorio nacional, para trascender a ser registrados legalmente por el poder rector central como ciudadanos con derechos básicos y no únicamente obligaciones. Dicha transformación cobró especial importancia en la actual fase de desarrollo del país debido a una doble situación: por un lado, a que "cada vez más nuestro tiempo de vigilia se desenvuelve con relación a las pantallas. A veces con ellas, otras a partir de ellas, otras más hacia ellas. Los procesos de recepción, uso y envío de mensajes mediante diversos canales, soportes, dispositivos y procedimientos analógicos y digitales constituyen, cada vez más y para más ciudadanos, el epicentro de su actividad cotidiana. La vida hoy es "una experiencia mediática" (Orozco y Franco, 2017, p. 16).
Por otro lado, "a la par de esta tendencia de audienciación, central en nuestra época de creciente intercambio, se desarrolla otra como su contraparte, que es la mediatización, por la cual nuestro conocimiento del mundo, del otro y de lo otro, cada vez más, se crea a través de pantallas, no de manera directa. Esto significa que lo que conocemos del otro y del mundo a través de las pantallas y las imágenes y sonidos por los cuales los demás nos conocen, son representaciones, no son los objetos o sujetos mismos, sino son construcciones o reproducciones de ellos. Esto siempre corre el riesgo de tener alteraciones o desviaciones y errores, tanto de percepción como de producción, o modificaciones intencionadas o fortuitas resultantes de los procesos de representación involucrados en la construcción de fidelidad y verosimilidad de objetos y sujetos" (Orozco y Franco, 2017, pp. 16 y 17).

Debido a ello, al hablar de los derechos de las audiencias no solo "se trata de que los medios solo cumplan con la programación ofrecida y lo hagan en los tiempos acordados, lo cual ya está contemplado en las regulaciones existentes; sino de que cuando se diga 'telenovela' sea eso y no una ficción híbrida que sirve de soporte y escaparate a la publicidad o a la propaganda política. También de que el derecho a la recepción sea respetado cuando se presenten 'noticias' que 
son opiniones o 'noticias' que son propaganda de candidatos o políticos que se hacen 'entrevistar' para venderse como fuentes de información real o fresca" (Orozco y Franco, 2017, p. 17).

Todo ello adquirió una doble relevancia especial cuando se observa que los contenidos que producen y programan las empresas de radio y televisión abierta y de paga son decisiones que adoptan unilateralmente sus directivos, donde las audiencias no participan en la elaboración de las políticas editoriales o en la producción de las temáticas de las barras programáticas, siendo una imposición del concesionario sobre la sociedad. Sin embargo, al ser infraestructuras de comunicación electrónicas que utilizan el espectro radioeléctrico o las redes públicas de telecomunicaciones (propiedades de la nación) para transmitir sus mensajes, lo cual implica que requieren el otorgamiento de una concesión por parte del Estado mexicano; estas quedan obligadas legalmente a desempeñarse como empresas de servicio público que exige la Constitución Política Mexicana y no solo como simples consorcios de lucro comercial. Razón suficiente para que tales industrias se apeguen rigurosamente al cumplimiento de los principios de los derechos humanos, las garantías de información, la pluralidad, la ética, la multiculturalidad y los derechos de las audiencias cautivas a las que atienden
("Derechos de las audiencias son un logro...", 2017).

De aquí, la enorme importancia que la sociedad civil le exija al Estado mexicano que cree claros y firmes Derechos de las $A u$ diencias que permitan que los públicos gocen de mayores garantías jurídicas para construir correctamente las bases cotidianas de su conocimiento personal del mundo y de la vida, mediante el cual se relacionan e interactúan diariamente con el resto de los individuos y las comunidades que los rodean.

\section{LA CONTRARREFORMA COMUNI- CATIVA CONTRA LOS DERECHOS DE LAS AUDIENCIAS}

Sin embargo, pese a los relevantes progresos constitucionales alcanzados en materia de reconocimiento de los Derechos de las Audiencias y de su sólida fundamentación jurídica por parte del Estado mexicano, paradójicamente los concesionarios privados de los medios electrónicos comerciales argumentaron que tales derechos, eran legalmente improcedentes y negativos, pues atentaban contra la libertad de expresión, la libertad de información, la libertad de empresa, introducían la censura, impedían la adecuada transmisión cotidiana de las noticias, etc. Derivado de ello, el Poder Ejecutivo y el Poder Legislativo emplazaron respectivamente dos controversias constitucionales ante la 
Suprema Corte de Justicia de la Nación (SCJN) para impedir el avance de estas garantías comunicativas de los ciudadanos largamente esperadas durante el siglo XX y principios del siglo XXI. Por un lado, la controversia del Poder Legislativo, a través del Senado de la República y, por otro lado, la controversia del Poder Ejecutivo, a través de su Consejería Jurídica.

Así, por una por parte, después de que el Senado de la República solicitó un punto de acuerdo el 23 de febrero el 2017 para la publicación urgente de los Lineamientos de los Derechos de las Audiencias, incoherentemente este poder republicano introdujo, el 30 de enero de 2017, una controversia constitucional contra el Instituto Federal de Telecomunicaciones (Ifetel) por la supuesta violación a los artículos $6^{\circ}, 7^{\circ}, 26^{\circ}, 28^{\circ}, 73^{\circ}$, $78^{\circ}, 94^{\circ}$ y $105^{\circ}$ de la Constitución Política Mexicana ("Controversia constitucional contra el Instituto Federal...”, 2017). Posteriormente, por otra parte, pese al respaldo público otorgado por el presiente Enrique Peña Nieto el 14 de julio de 2014 en la ceremonia de promulgación de la Ley Secundaria de la reforma constitucional, para reconocer la valía de tal legislación y el profesional trabajo ejecutado por el Ifetel en el campo de la radiodifusión (Solórzano, 2017, pp. 13-14), contradictoriamente, el 31 de enero de 2017 la Consejería Jurídica del Po- der Ejecutivo interpuso otras inconformidades más contra la Cámara de Diputados y la Cámara de Senadores por haber creado, a través de los artículos 15, fracción LIX, 216, fracción II y 256 al 261 de la Ley Federal de Telecomunicaciones y Radiodifusión, diversas normas que sostenían atentaban contra los postulados de la Carta Magna en la materia ("Controversia constitucional contra los artículos...”, 2017).

Mediante tales acciones jurídicas el Poder Mediático en alianza con el Poder Ejecutivo y el Poder Legislativo intentaron debilitar la autonomía del Ifetel que tardó décadas en crearse para establecer mayores equilibrios dentro del ámbito de las telecomunicaciones y la radiodifusión en México; para evitar que existiera un órgano independiente que regulara el funcionamiento de los procesos de comunicación en el espacio púbico mediático.

Posteriormente a tales demandas, sin esperar el veredicto final de la Suprema Corte de Justicia de la Nación sobre las dos controversias constitucionales interpuestas por el Poder Ejecutivo y el Senado de la República sobre la validez de los derechos de las audiencias, sorpresivamente se inició en la Cámara de Diputados un proceso de "contrarreforma comunicativa" para debilitar nuevamente al Ifetel y abolir los derechos de las audiencias. Así, sin respetar la división de poderes republicanos, pues se practicó una 
intromisión contra el Poder Judicial de la federación al no esperar la resolución de la Suprema Corte (González, 2017, p. 7); la Cámara Baja se adelantó y aprobó concertadamente analizar en forma paralela diversas iniciativas por separado para modificar la Ley Federal de Telecomunicaciones y Radiodifusión (LFTR) que presumiblemente atentaba contra los derechos de las audiencias, así como contra las facultades excesivas del Ifetel para normar tales garantías comunicativas. Con ello, no solamente se gestó un madruguete o albazo legislativo por parte de la Cámara de Diputados, sino que se permitió que los radiodifusores se blindaran anticipadamente para evitar que la Corte pudiera fallar en su contra definiendo que la regulación sobre las audiencias era correcta como estaba inicialmente reconocida en la LFTR, y con ello, rechazar las dos controversias constitucionales por la mala fundamentación jurídica de la Presidencia y del Congreso (González, 2017).

De esta forma, fueron presentados en la Cámara de Diputados dos proyectos que se les bautizó ante la opinión pública y las redes sociales como la Ley Televisa-II, o "LeyTelevisa-Döring-Limón, o Ley Televisa-Anaya: la primera, fue sustentada por el diputado por Movimiento Ciudadano (MC), Clemente Castañeda Hoeflichm, que propuso la eliminación de la distinción entre opinión e in- formación; la segunda fue expuesta por el diputado del Partido Acción Nacional (PAN) Federico Döring Casar, que planteó que se debía impedir que se aprobara la iniciativa que demandaba que se realizara la distinción entre publicidad e información, así como derogar facultades que le correspondían al órgano autónomo Ifetel para regular, vigilar y sancionar en materia de derechos de las audiencias (Cuauhtémoc, 2017).

Por ello, dicho proceso contra el legislativo fue denominado como la Ley Televisa-II, pues fue muy similar al realizado entre 20052006 en el Palacio Legislativo de San Lázaro, cuando en la fase preelectoral de ese momento, 257 diputados de PRI y PAN aprobaron, en solo siete minutos, sin haberla leído, la llamada Ley Televisa-I que otorgaba un enorme poder de concentración y de fuerza política a esa empresa y al resto de los medios masivos de difusión electrónicos en México por encima de los poderes constitucionales de la República (Méndez y Garduño, 2017, p. 16). De igual forma, asombrosamente, 12 años después, el 5 de abril de 2017, en los tiempos preelectorales de la renovación de los poderes públicos de cuatro gobiernos (Estado de México, Nayarit, Coahuila y Veracruz) y de la proximidad de la elección presidencial en 2018, se presentó y votó favorablemente en Comisiones la Contrarreforma Comunicativa, con el aval de 14 
votos a favor y tres en contra, en "lo oscurito”, en la Cámara de Diputados, a puerta cerrada, en unos minutos, casi por unanimidad y sin darle lectura previa, contraviniendo los derechos de las audiencias reconocidos en el corazón de la Constitución Política Mexicana (Méndez y Garduño, 2017, p. 16).

Así, debido a que la Reforma en Telecomunicaciones y Radiodifusión del 2013 incorporó obligaciones legales básicas cuyo cumplimiento incomodó seriamente a un sector muy poderoso de la industria de la radiodifusión, un grupo amplio de legisladores y del gobierno revirtieron los avances civilizatorios logrados en materia de derechos de las audiencias después de una larga lucha de más de 65 años de la sociedad mexicana para consolidar sus garantías comunicativas elementales que le correspondían ejercer desde hace un siglo ("El regreso de la Ley Televisa...", 2017). Es decir, fue la imposición legislativa autoritaria de los poderes fácticos mediáticos y de su telebancada en el Congreso que solo representaron los intereses dominantes de los grandes consorcios monopólicos de la radiodifusión, que se ejecutó dicho retroceso justo antes de la celebración de otro de los procesos electorales más álgidos de los últimos años en el país.

Este escandaloso y preocupante episodio regresivo sobre los derechos comunicativos mostró claramente como las institucio- nes del Estado fueron utilizadas burdamente por los imperios que dominan el sector de la radiodifusión y lograron doblar al Ifetel como órgano constitucional autónomo minando sus facultades. En pocas palabras, presenciamos el embate de los poderes fácticos mediáticos contra las instituciones republicanas del Estado-nación y la sociedad en su conjunto, logrando poner a su servicio al Poder Ejecutivo y a una parte del Poder Legislativo con el fin de defender sus intereses comerciales monopólicos. Todo ello, con el fin de congraciarse con el poder de los industriales de la radiodifusión privadocomerciales con miras a que sus proyectos políticos y económicos fueran apoyados en los procesos electorales estatales del 2017 y en los federales del 2018 en México (Calleja, 2017).

De aquí, la gran importancia que la academia, la sociedad civil y las escuelas de comunicación organizadas demanden al Estado el respeto y ejercicio riguroso del modelo de comunicación de servicio público como el eje fundamental de instrumentación de la Reforma de las Telecomunicaciones y de la Radiodifusión reconocida por la Carta Magna que respalda el cumplimiento irrestricto de las garantías comunicativas básicas para construir otro modelo de comunicación que nos permita ser auténticamente ciudadanos en la segunda década del siglo XXI. De otra for- 
ma, en plena Cuarta Revolución Industrial permaneceremos solo como espectadores de la consolidación del nuevo Capitalismo Informacional de Compadres y de la voraz "modernidad" globalizada que impulsan los inmensos consorcios privados de la comunicación comercial en la Republica, abortándose la creación de la sociedad de la comunicación que es el gran desafío elemental de México en el tercer milenio. 


\section{FUENTES CONSULTADAS}

"Acuerdo mediante el cual el pleno del Instituto Federal de telecomunicaciones aprueba y emite los lineamientos generales sobre la defensa de las audiencias" (2016). Tomo DCCLIX, núm. 15, Quinta Sección, Diario Oficial de la Federación (DOF), Secretaría de Gobernación (Segob), Poder Ejecutivo, Gobierno de México, Ciudad de México, México, 21 de diciembre de 2016, 102 páginas (versión larga), http:/ /www.dof.gob.mx/nota_detalle.php?codigo $=5466365 \&$ fecha $=21 / 12 / 2016$.

"Controversia Constitucional contra el Instituto Federal de Telecomunicaciones (Ifetel) por violación a los artículos $6^{\circ}, 7^{\circ}, 26^{\circ}, 28^{\circ}, 73^{\circ}, 78^{\circ}, 94^{\circ}$ y $105^{\circ}$ de la Constitución Política Mexicana" (2017). Senado de la República, LXIII Legislatura, Poder Legislativo, Gobierno de México, Ciudad de México, 30 de enero, 96 páginas.

“Controversia Constitucional contra los artículos 15, fracción LIX, 216, fracción II y 256 al 261 de la Ley Federal de Telecomunicaciones y Radiodifusión” (2017). Consejería Jurídica, Presidencia de la República, Poder Ejecutivo Federal, Gobierno de México, Ciudad de México, 31 de enero, 37 páginas.

"Derechos de las audiencias son un logro que no debe regatearse" (2017). Asociación Mexicana de Derecho a la Información (AMEDI), Ciudad de México, México, 26 de enero, recuperado el 31 de mayo de 2017 de http://www.amedi.org.mx/derechos-de-las-audiencias-son-un-logroque-no-debe-regatearse/, 5 páginas.

"El regreso de la Ley Televisa y la amenaza a las audiencias", (2017). En: AltoNivel, Sección Telecomunicaciones, Ciudad de México, México, 25 de abril de 2017, recuperado el 14 de mayo de 2017 de http://www.altonivel.com.mx/regreso-la-ley-televisa-la-amenaza-a-lasaudiencias $/$ ?utm_source $=$ Bolet $\%$ C3\%ADn+AMEDI\&utm_campaign $=5$ ca82e50e6-

EMAIL_CAMPAIGN_2016_11_04\&utm_medium=email\&utm_term=0_d2ee7c4b8c5ca82e50e6-91449672\#.WP9NV1345f0.facebook.

“Elecciones 2000. Cuánto gastaron los partidos políticos en la tv. Informe”, (2002). Revista Etcétera, núm. 25, Una Ventana al Mundo de los Medios, México, DF, noviembre.

"Encuesta nacional de hábitos, prácticas y consumos culturales". (2010), Consejo Nacional para la Cultura y las Artes (Conaculta), Gobierno de México, México, DF, agosto.

“Informe ENCUP 2008” (Encuesta Nacional sobre Cultura Política y Prácticas Ciudadanas), Secretaría de Gobernación (Segob), Secretaría de Relaciones Exteriores (SER) e Instituto 
Internacional para la Democracia y la Asistencia Electoral (IDEA), México, DF, diciembre, www.encup.gob.mx.

"La impunidad en México" (2003). Comisión Mexicana de Defensa y Promoción de los Derechos Humanos y Comisión Interamericana de Derechos Humanos, México, DF, 26 de febrero.

"Sesión de aprobación con 288 votos a favor, 114 en contra y 18 abstenciones, de la reforma en telecomunicaciones para quitar al Ifetel la facultad de normar el derecho de audiencia" (2017). Cámara de Diputados, Palacio de San Lázaro, Congreso de la Unión, Poder Legislativo, Gobierno de México, Ciudad de México, abril 28, en: Aristegui Noticias, recuperado el 4 de mayo de 2017 de http://aristeguinoticias.com/2804/mexico/asi-fue-eldebate-en-san-lazaro-por-ley-televisa-doring-video/.

“Televisa y la clase media” (2000). Revista Proceso, México, DF, 15 de febrero de 1993, en: Aires de familia. Cultura y sociedad en América Latina, XXV Premio Anagrama de Ensayo, Anagrama, México, DF.

Caballero Pedraza, V. (2014). "Insuficiente, lo aprobado por diputados: Especialistas", en: Revista Zócalo, núm. 168, año XIV, Comunicación, Política y Sociedad, México, DF, febrero. Calleja, A. (2017). “Audiencias, en juego algo más que los derechos”, en: La Silla Rota, Sección Opinión, Ciudad de México, México, 14 de febrero, recuperado el 16 de mayo de 2017 de http://lasillarota.com/opinion/columnas/audiencias-en-juego-algo-mas-que-los-

derechos/138602\#.WKMiB7bhAUE.

Contreras Rodríguez, N. (2012). "Los estratos sociales en México”, Universidad Tecnológica de Tijuana, Tijuana, Baja California, México, 28 de septiembre, recuperado el 24 de marzo de 2014 de http://www.slideshare.net/neriberth/estratos-sociales-en-mexico-neri-no.

Esteinou Madrid, J. (2001). "Las Industrias Culturales y el Modelo de Comunicación Mercado", en: Revista Convergencia, núm. 25, año 8, Revista de Ciencias Sociales, Facultad de Ciencias Políticas y Administración Pública, Universidad Autónoma de Estado de México (UAEM), Toluca, Estado de México, México, mayo-agosto.

. (2011). "Elecciones, comunicación política y límites de la democracia", autores varios, en: Comunicación Política y Democracia, Colección Sinergia, núm. 11, Dirección Ejecutiva de Capacitación Electoral y Educación Cívica, Instituto Electoral del Distrito Federal (IEDF), México, DF, diciembre. 
- (2011-B). "Los monopolios comunicativos y su lucha contra la democracia en México", en: Anuario de Investigación 2010, Colección Anuarios de Investigación, Departamento de Educación y Comunicación, Universidad Autónoma Metropolitana, Unidad Xochimilco (UAM-X), México, DF, diciembre.

- (2012). "Elecciones, modelos de comunicación y edificación de la democracia deliberativa en México", en: Anuario de Investigación 2011, Colección Anuarios de Investigación, Departamento de Educación y Comunicación, Universidad Autónoma Metropolitana, Unidad Xochimilco (UAM-X), México, DF, junio.

(2013a), 'Del 'Modelo de Comunicación para los Jodidos' a la 'Reforma

Constitucional de las Telecomunicaciones' en México", Seminario "La Reforma Constitucional de las Telecomunicaciones y el Cambio del Modelo de Comunicación en México", Vocalía del Valle de México, Consejo Nacional para la Enseñanza e Investigación de las Ciencias de la Comunicación (CONEICC), Escuela de Periodismo Carlos Septién García (EPCSG), Universidad Autónoma Metropolitana, Unidad Xochimilco, Auditorio Principal, Escuela de Periodismo Carlos Septién García, México, DF, 27 de junio.

. (2013b), "Otra comunicación política, para otra democracia en México”, en:

La complejidad de la comunicación política: actores y escenarios, Mendieta Ramírez A., Castillo Durán J.L. y Rodríguez Escobedo F. J. (coordinadores), Consejo Nacional de Ciencia y Tecnología (Conacyt), Benemérita Universidad Autónoma de Puebla (BUAP), Montiel \& Soriano SA, Puebla, México, noviembre.

. (2013c). "Telecracia VS democracia: las elecciones del 2012”, en: República de telenovela. Medios, campañas y elección 2012, García Calderón C. (coordinadora), Seminario Interdisciplinario de Comunicación e Información, Comunicación y Política Editores, México, DF, febrero.

Fernández, C. y Pasman, A. (2001). “El Tigre. Emilio Azcárraga y su imperio Televisa”, Editorial Mondadori, Colección Mitos de Bolsillo, México, DF, 670 páginas.

Navarro Benítez, R. (2013). “Desde México, la voz de Norteamérica para América: la imposición del modelo comercial estadounidense de radiodifusión a través de los empresarios 'nacionales"', en: Revista El Cotidiano, núm. 181, año 28, Revista de la Realidad Mexicana Actual, División de Ciencias Sociales y Humanidades, Universidad Autónoma Metropolitana, Unidad Azcapotzalco, México, DF, septiembre-octubre. 
Orozco, G. y Franco, D. (2017). "El daño a la libertad de expresión”, en: Revista Zócalo, núm. 205, año XVII, Política, Comunicación y Sociedad, Ciudad de México, marzo.

Solórzano Fuentes, A. (2017). “¿Quién debe regular los derechos del público?”, en: Revista Zócalo, núm. 205, año XVII, Política, Comunicación y Sociedad, Ciudad de México, marzo.

Vázquez Mota, J. (2005). "Sociedad civil y medios de comunicación”, Simposio "Sociedad Civil y Medios de Comunicación. El Despertar del Receptor”, Secretaria de Desarrollo Social, Gobierno de México, Centro Mexicano de Filantropía, (Cemefi), Hotel Camino Real, México, DF, 8 y 9 de noviembre, versión estenográfica.

Zabludovsky, A. (2002). "El duopolio televisivo", Director General de Conexión Financiera, en: Los medios electrónicos en el marco de la reforma del Estado, Fundación Konrad Adenauer y H Cámara de Diputados, México, DF, diciembre.

\section{HEMEROGRÁFÍA}

"Favorecen en 2000 televisoras al PRI" (2003). Periódico Reforma, México, DF, 4 de noviembre.

"La Ley no regula descuentos" (2003). Periódico Reforma, México, DF, 4 de noviembre.

"La violencia televisada produce graves y prolongados daños síquicos en los niños" (1992).

Periódico Excélsior, México, DF, 8 de agosto.

"Los mexicanos pasan más horas frente a la televisión” (1998). Periódico El Nacional, México, DF, 7 de abril.

"Rinde menos dinero de PRD en televisión" (2003). Periódico Reforma, México, DF, 4 de noviembre.

“Sociedad civil al rescate" (2003), Periódico El Universal, México, DF, 7 de marzo.

“Televisa no está vinculada al poder ni a la política” (1993), Periódico El Nacional, México, DF, 11 de febrero.

"Un estudio reveló que los mexicanos son los que más tiempo pasan frente a la televisión en América" (1998). Periódico Crónica, México, DF, 7 de abril.

"Ve $81 \%$ de los menores la tv sin supervisión" (2005). Periódico El Universal, México, DF, 19 de noviembre.

Cuauhtémoc Cruz, I. (2017). “\#LeyTelevisaDöring: el nuevo atentado contra las audiencias”, La Jornada de Oriente, Columna Medieros, Sección Opinión, Tlaxcala, México, 12 de abril de 2017, recuperado el 15 de mayo de 2017 de http://www.lajornadadeoriente.com.mx/2017/04/12/leytelevisadoring-nuevo-atentado-las- 
audiencias $/$ ?utm_source $=$ Bolet $\% C 3 \% A D n+A M E D I \& u t m \_c a m p a i g n=8 a f c 5 a 3100$ -

EMAIL_CAMPAIGN_2016_11_04\&utm_medium=email\&utm_term=0_d2ee7c4b8c8afc5a3100-91449672.

Gómez Leyva, C. (2003). “La televisión no hace milagros”, Periódico Milenio, México, DF, 6 de noviembre.

González, S. (2017). "El dictamen aprobado en la Comisión de Radio y TV es regresivo: Amedi”, Periódico La Jornada, Sección Política, Ciudad de México, México, 7 de abril.

González, A. (2017). “Acusan madruguete en audiencias”, Periódico Reforma, Sección Voto 2017, Ciudad de México, México, 5 de abril, recuperado el 10 de mayo de 2017 de http://www.reforma.com/aplicacioneslibre/preacceso/articulo/default.aspx?id=1083404\& urlredirect=http://www.reforma.com/aplicaciones/articulo/default.aspx?id=1083404.

Méndez, E. y Garduño, R. (2017). “Avalan en comisiones reforma que elimina facultades al Ifetel”, Periódico La Jornada, Sección Política, Ciudad de México, México, 26 de abril. 